\title{
Some aphorisms of psychiatric rehabilitation
}

\author{
Douglas Bennett
}

During my years in rehabilitation and community psychiatry I have picked up a number of aphorisms which I believe enshrine some of the lasting truths in this field. I have always liked Albert Kushlik's remarks about doctors as the "hit and run" staff in terms of the duration of their contact with patients. But over the years other aphorisms have been brought to my attention by colleagues or students, although I can claim to have coined a couple myself.

The first is 'Upside Down Psychiatry' which was stimulated by the idea that the most severely ill psychiatric patients are often served by the less trained, the less skilled, if not the less exper1enced but more institutionalised staff. Those staff might be nurses, social workers, or psychiatrists. The more highly trained staff are usually in university hospitals dealing with patients whose clinical and social problems are much less severe. It is essential that psychiatry turns the right way up and recognises the urgent, if less exciting, needs of the most severely and enduringly mentally ill for the most skilled assistance.

The second saying relates to teamwork and was coined by a psychologist colleague. It refers to the essential quality of teamwork. "No implementation without participation" seems to echo the "no taxation without representation" theme of the American Revolution. But it recognises that every member of a team should participate in whatever decisions are made for a psychiatrically disabled individual's care. If this does not happen the team's plan will not be realistic in its aims and it will not be effectively implemented.

In community work it has to be appreciated that there is "a dignity of risk". This was brought to my attention when a staff member wrote up a study of about 20 marriages between two patients which certainly in previous decades were regarded as risky. As readers know, doctors are not anxious to take risks but risk is an essential part of social life. You cannot treat people in the community as if they were in a hospital. In the words of a recent English inquiry into community care for the severely mentally ill, community care means "transplanting some of the complex organisational and risk management aspects of the hospital into an 'open', ever-changing com- munity, with many different agencies providing care and few unifying structures". In spite of the risk almost all the marriages did well and both partners gave support to each other. In community living there are lower levels of dependency, higher levels of satisfaction and higher standards of care.

Another study was undertaken on some very severely disabled psychotic patients who, having been discharged after many years as in-patients. were allowed to attend the hospital ward on days when they wished. They obviously welcomed this dispensation: although they attended more frequently than the more active and communicative former patients, they only sat and made little social contact or conversation with staff or other patients. Bulmer (1987) says that those who, lacking social contacts, live in isolation appreciate that the ability to come to the ward after discharge demonstrates the hospital's concern for their well-being. They taught us that some patients have a need for "contact without intimacy".

At one time nurses in mental hospitals thought that supporting patients would make them 'hammock-dependent' on the hospital and one article, written for nurses, defined rehabilitation as 'the progresstve withdrawal of support'. This was a false proposition and led another of my psychologist colleagues to coin the phrase that "the denial of support is the denial of disability" a phrase more easily understood, perhaps, in terms of denying a stick to a lame man.

One of the greatest unrecognised obstacles in rehabilitation and community care is the "Solidarity of the Sane". The sane, who make up the bulk of the population, see themselves as totally different from those who have some form of mental disorder. Their anxiety to maintain the solidarity of their group makes it difficult for them to change their views and make life easier for the disabled psychiatric patient. It becomes impossible to follow the example of those who rehabilitate the physically disabled, improving their adaptation by modifying their physical environment. In the same way altering the views and the behaviour of other people will change the psychiatrically ill persons' environment and aid 
their rehabilitation. Unfortunately, this change is hindered by the solidarity of the sane.

Many rehabilitation psychiatrists take an unduly optimistic view of the possible outcome of their practice; since not all our disabled clients have the capacity to improve. Some do not improve for reasons that we do not yet understand. But these unfortunates must still be rehabilitated if their disabilities are not to impair their functioning still further. We have to remind ourselves that "some disabled psychiatric patients need sustenance for they cannot grow."

One sad observation based on experience is that when the team agrees about a patient's diagnosis or perhaps more importantly prognosis then that patient has "had it". Every person or patient has some less admirable features as well as good qualities. The latter will only be recognised when some member of the team, old. young, male, female, experienced or beginner, speaks up and draws attention to them.

It is a rare but worrying occasion when this does not happen and one is faced with the staff's damning agreement.

Let me finish with a more cynical phrase coined by a distinguished friend who has worked for many years with long stay and long term psychotic patients in both hospital and community. He noticed that some of these patients recovered and returned to the community after a key relative (often a mother or more rarely someone else) had died. He decided that, in these situations, "While there's death there's hope".

\section{Achowiedgements}

I gratefully acknowledge the help and ideas of Dr James Birley, Professor Geoff Shepherd, Isobel Morris and other insightful colleagues.

\section{Reference}

BULMER, M. (1987) The Social Basis of Community Care. London: Allen and Unwin.

Douglas Bennett, Emeritus Consultant Psychiatrist, Bethlem Royal and Maudsley Hospitals $/$

Correspondence: 5 Mill Lane, Iffley, Oxford OX4 4EJ 